DOI: http://dx.doi.org/10.5007/2175-7941.2014v31n1p198

\title{
Resenha Science and the Citizen: Contemporary Issues and Controversies
}

Marco Mamone Capria (editor)

Editora Lulu Press, Raleigh, US, 2013, 1르 edição, 450 p

ISBN: 9781291446838

Palavras-chave: Ciência. Democracia. Controvérsias.

Keywords: Science. Democracy. Controversies.

Este livro originou-se de um projeto internacional denominado Ciência e Democracia: $<$ http://www.dmi.unipg.it/mamon e/sci-dem/>. Este projeto tem sido coordenado desde a sua criação por Marco Mamone Capria, o editor deste livro. Ele é professor do Departamento de Matemática da Universidade de Perugia na Itália. Pesquisa e ensina sobre geometria, teoria da relatividade, história e filosofia da ciência. Já editou diversos livros (CAPRIA, 1999, 2003, 2005 e 2006).

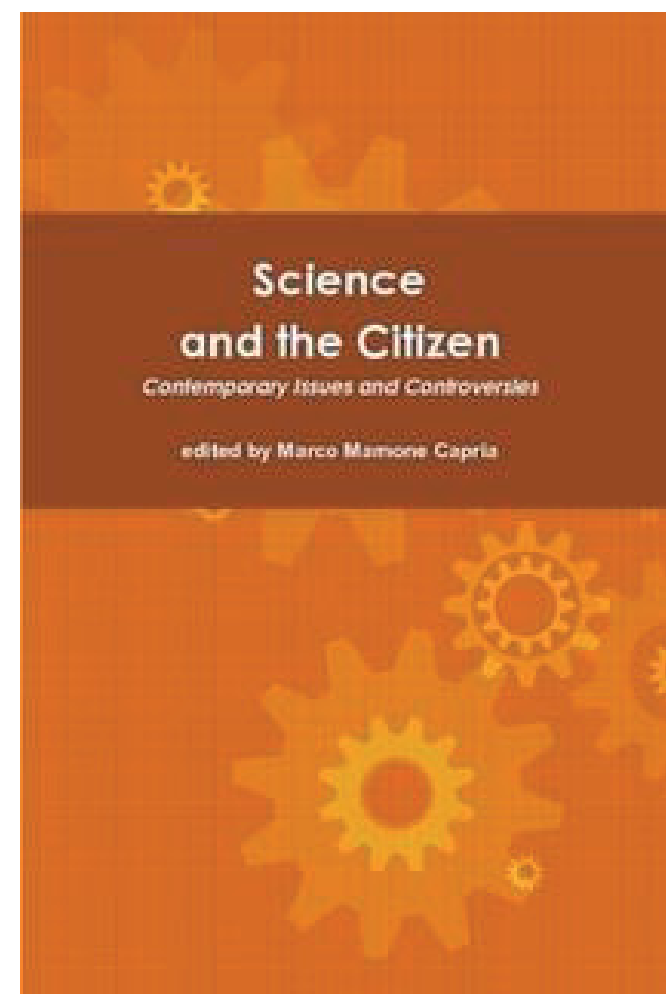

+Review of "Science and the Citizen: Contemporary Issues and Controversies" 
O livro é composto de 18 artigos, sendo que a maioria deles foi apresentada na quinta conferência Ciência e Democracia que ocorreu em Nápoles, em 2011. Todas estas conferências (2001, 2003, 2005, 2008 e 2011) ocorreram no Palazzo Serra di Cassano. Dentre os três anais já publicados, este é o primeiro em inglês. É um livro extremamente interessante, pois lida com assuntos controversos em diversas áreas da ciência: a relação entre democracia e os grandes projetos científicos, a influência das grandes corporações na medicina, o papel da tecnologia na vida moderna, o conflito entre o crescimento econômico e o meio ambiente, energia nuclear e nanotecnologia, a origem da AIDS, transplante de órgãos, ataques terroristas, delatores e heréticos na ciência, etc. No Prefácio, o editor informa que esta variedade de tópicos almeja mostrar que a desinformação associada com os principais meios de comunicação não é acidental ou ocasional, mas sim algo sistêmico que serviria para os objetivos de propaganda para os quais estes meios de comunicação foram criados e estão sendo financiados.

O primeiro artigo do livro, escrito pelo editor, apresenta diversos argumentos a favor da ideia que a ciência tecnológica ocupa hoje em dia o lugar deixado pela religião como sendo a principal ferramenta ideológica para reprimir ou prevenir os protestos políticos e as reivindicações dos grupos oprimidos. Segundo Capria, isto é feito tanto pelas promessas apresentadas pela ciência, quanto pelos "milagres" obtidos pela tecnologia. Tudo isto seria realizado com a ajuda dos grandes meios de comunicação. Ou seja, haveria um cientificismo reacionário funcionando como uma espécie de religião para grande parte da população desinformada. Em uma seção interessante de seu artigo ele mostra que novas tecnologias não são sempre necessárias e não melhoram obrigatoriamente a qualidade de vida.

$\mathrm{O}$ artigo de M. T. Brown e S. Ulgiati discute facetas opostas da democracia, tais como o crescimento econômico e os danos ao meio ambiente. Os autores concluem que o crescimento a qualquer custo não é uma boa opção para qualquer sociedade saudável, já que acaba trazendo, a longo prazo, mais problemas do que soluções. É interessante lembrar aqui de um livro muito bem escrito discutindo diversos colapsos de sociedades ao longo da história (DIAMOND, 2005). Como mencionado neste artigo, o problema não é apenas a disponibilidade de recursos, nem em como encontrar outras fontes de energia. O principal problema é de continuar procedendo como sempre. As consequências ambientais, econômicas e sociais de uma energia sempre barata podem ser ainda piores do que os limitados combustíveis fósseis. Os autores argumentam que em vez de tentar resolver os problemas atuais de crise de energia aumentando os gastos e procurando novas fontes, 
deveríamos focar nossas atenções em como viver de maneira responsável com as capacidades limitadas oferecidas pelo nosso planeta.

Há um artigo muito bem escrito pelo brasileiro Jenner Barretto Bastos Filho mostrando como uma atividade científica separada da ética é prejudicial para a própria ciência. Ele é professor do Departamento de Física da Universidade Federal de Alagoas, trabalhando nos fundamentos da física, história e filosofia da ciência, educação ambiental, além do ensino de física. Tem diversos artigos e dois livros publicados sobre estes temas (BASTOS FILHO, 1999 e 2005), além de ter editado outros dois livros com outros autores (BASTOS FILHO; SIQUEIRA, 1997; BASTOS FILHO; AMORIM; LAGES, 1999). Jenner utiliza uma argumentação muito interessante para embasar sua análise. Ele cita alguns cientistas famosos que tiveram atitudes éticas ruins em alguns aspectos de suas vidas (Edward Teller, Fritz Haber, Luis Alvarez, Albert Einstein e outros) para então argumentar que embora a boa atividade científica possa coexistir com baixos princípios éticos, a aceitação desta situação é contraprodutiva para o progresso da ciência. Em seguida ele analisa diversos aspectos que dão sustentação à sua argumentação seja no aspecto dos grandes projetos científicos, seja no desenvolvimento econômico dos países, entrando também na questão da ciência médica e da indústria farmacêutica. É um artigo que merece ser discutido nos cursos de história e filosofia da ciência.

Quatro artigos deste livro discutem o papel dos cientistas com a democracia participativa. Fabrizio Fabbri, por exemplo, enfatiza a importância da participação pública nas novas ciências e tecnologias que estão surgindo a todo o momento. Ele defende que esta participação popular é importante para prevenir conflitos sociais. Um dos principais tópicos de seu artigo diz respeito aos organismos geneticamente modificados e os riscos que eles trazem para toda a sociedade. Ele também discute os conflitos de interesse dos políticos e dos cientistas que trabalham nas grandes empresas multinacionais. Já Simon Maurano discute os riscos ambientais focando principalmente no recente problema da coleta e tratamento de lixo que afetou a Itália. Os problemas científicos e ambientais ligados com a energia nuclear, tanto a nível mundial quanto especificamente da Itália, foi analisado por Sergio Ulgiati e Patrizia Ghisellini. Foi discutido o acidente de Fukushima, o lixo radioativo, os problemas de poluição em comparação com os combustíveis fósseis, as tomadas de decisões pelos governos (juntamente com as sociedades científicas e com os especialistas técnicos) no que diz respeito às opções energéticas etc.

Um artigo muito interessante que me chamou a atenção, escrito em um estilo bem diferente dos outros trabalhos do livro, é o de Sergio Siminovich: "No Início era... o Prazer! Amadores e Profissionais na Música e em outras áreas." Ele foi fundador e diretor artístico do coro do Centro Italiano de Música Antiga, assim 
como Diretor do Departamento de Música Coral na Faculdade de Artes da Universidade de La Plata, em Buenos Aires. Neste artigo ele compara o papel dos profissionais ou especialistas com o papel dos diletantes ou amadores. Ele descreve aquilo que denominou de experiências musicais nas quais ensinou peças difíceis e importantes do repertório barroco para um coral composto de amadores sem formação técnica na música. Mostrou que eles podiam não apenas cantar com qualidade comparável aos profissionais, mas também podiam aprender a reger como um maestro especialista. Os motivos que o levaram a esta tentativa de democratização da música foram bem conscientes, a intenção de desconsagrar os instrumentos de poder, eliminando a separação entre os profissionais e a população em geral. Ele queria também levar as pessoas comuns a descobrirem coisas novas, a se questionarem sobre o saber, além de permitir a elas o prazer da própria atividade musical. No final deste belo artigo ele ainda levanta a possibilidade de estender esta prática a outras áreas da ciência, tais como física, biologia, matemática ou filosofia. Ele próprio se propõe a colaborar com quem quiser começar uma experiência deste tipo, convidando os interessados a lhe enviar um email: <sersiminovich@yahoo.com.ar>.

Cinco artigos deste livro são dedicados exclusivamente à medicina corporativa. É analisada a influência da indústria farmacêutica, os conflitos de interesse dos médicos e cientistas, até que ponto a medicina é realmente baseada em evidências, a relação entre algumas vacinas e as mortes relacionadas a este procedimento, etc. Alguns autores discutem diversos aspectos controversos ligados à síndrome da imunodeficiência adquirida (AIDS ou SIDA): As possibilidades de os remédios para a AIDS causarem mais doenças e complicações médicas do que curas, se realmente já está comprovado que esta doença é causada pelo vírus da imunodeficiência humana (HIV ou VIH) ou se isto não passa de um preconceito perigoso e que está levando a pesquisa nesta área para o caminho errado. Outros autores discutem as experiências com animais e as controvérsias ligadas a este tema: Os aspectos éticos e morais associados com esta prática, até que ponto os resultados destas experiências com animais podem ser utilizados com seres humanos etc. Um artigo interessante do médico Rocco Maruotti discute especificamente os aspectos éticos ligados aos transplantes e os diferentes papéis assumidos por cirurgiões e por todos envolvidos neste processo. Ele mostra como a própria definição de morte tem mudado nos últimos anos. Por milhares de anos este conceito estava associado à parada cardíaca e de funcionamento do pulmão. Ultimamente foi introduzida a morte cerebral, que pode ocorrer mesmo com o coração continuando a bater e com o paciente ainda respirando (com diferentes definições técnicas de quando o cérebro teria parado de funcionar), além de várias outras definições discutidas no arti- 
go. É também analisada detalhadamente a questão da obtenção e doação de órgãos para transplantes, como o papel e os direitos do doador tem variado ao longo dos últimos anos e em diferentes sociedades, o papel dos coordenadores de transplantes e de todos os outros profissionais envolvidos nestes procedimentos, assim como os incentivos nem sempre morais ou éticos que são utilizados para forçar a doação. É um artigo denso, que nos faz pensar e refletir bastante sobre um assunto muito delicado.

Tem também um artigo muito detalhado e cuidadoso escrito pelo editor, Marco Capria, em colaboração com Marcos Cesar Danhoni Neves, criticando a explicação oficial fornecida pelo governo americano para o atentado de onze de setembro de 2001. Marcos Neves é professor titular do Departamento de Física da Universidade Estadual de Maringá, UEM. É muito ligado à área de ensino de física e astronomia, já tendo publicado diversos artigos e livros sobre o tema tais como, por exemplo, (NEVES, 2004, 2008; NEVES; ARGÜELLO, 2001). Os autores começam apresentando diversos fatos ligados a este atentado, em seguida apresentam a versão oficial do que ocorreu neste fatídico dia, para em seguida mostrar um número enorme de contradições contidas nesta versão. Eles discutem o papel da grande imprensa no sentido de apresentar uma versão deformada dos fatos e de influenciar a opinião pública, a maneira como os dissidentes são silenciados, além de chamarem a atenção para diversos movimentos e associações públicas que têm sido formadas nos últimos anos exigindo que toda a verdade seja esclarecida. Eles discutem até mesmo as implicações educacionais relacionadas a todo este processo. É um artigo que exigiu muito esforço para ser escrito já que juntou uma grande quantidade de fatos e informações, com 56 páginas, listando 13 vídeos e citando 85 referências. Merece ser lido com atenção e amplamente discutido.

O livro contém ainda uma longa entrevista concedida a Anthony Liversidge pelo matemático Serge Lang (1927-2005) em 1993. Ela é seguida por um artigo do Marco Capria discutindo a vida e a obra de Lang. Ele teve uma grande produção acadêmica, sendo professor nas universidades de Chicago, Columbia e Yale. Ficou também famoso por suas controvérsias e envolvimento político. Opôsse à guerra do Vietnã e lutou contra a má informação na ciência. Manteve longa correspondência com diversos cientistas e chegou a publicar arquivos polêmicos contendo estas cartas e outros documentos pessoais. Foi um cientista engajado politicamente e ativista em muitas frentes. De acordo com Capria, os trabalhos de Lang sobre a prática científica apresentam algumas das contribuições mais importantes para se compreender a sociologia da ciência contemporânea.

O livro termina com um artigo do jornalista Anthony Liversidge descrevendo suas impressões pessoais ao ter participado da segunda conferência Ciência 
e Democracia, ocorrida em 2003, com tantos hereges que questionam diversos aspectos da ciência moderna. Analisa a censura na academia e conta diversos fatos interessantes ocorridos durante a conferência, menciona a personalidade de diversos participantes etc. Entre outras coisas chama a atenção para a luta de Marcos Neves para mostrar que Santos Dumont é quem deve ser considerado o pai da aviação, em vez dos irmãos Wright (NEVES, 2003). Também menciona a apresentação de Halton Arp questionando a teoria padrão da expansão do universo. Arp já tem um livro traduzido em português sobre este tema (ARP, 2001). Ele cita também o documentário produzido por Randall Meyer discutindo a obra de Arp (MEYERS, 2004).

A principal deficiência que encontrei neste livro que trata de assuntos tão diversos foi uma pequena biografia dos autores de cada capítulo. No mais, é uma obra excelente que deve ser indicada aos alunos de todas as áreas da ciência no sentido de formar espíritos críticos e cidadãos conscientes.

\section{Referências Bibliográficas}

ARP, H. O Universo Vermelho: Desvios para o Vermelho, Cosmologia e Ciência Acadêmica. Tradução: A. K. T. Assis e D. S. L. Soares. São Paulo: Perspectiva, 2001.

BASTOS FILHO, J. B. O que é uma teoria científica? Uma breve provocação sobre um tema complexo. 2. ed. Maceió: Edufal, 1999.

BASTOS FILHO, J. B. Reducionismo (uma abordagem epistemológica). Maceió: Edufal, 2005.

BASTOS FILHO, J. B.; AMORIM, N. F. M.; LAGES, V. N. (Orgs.). Cultura e desenvolvimento (a sustentabilidade em questão). Recife: Editora Universitária da Univ. Fed. de Pernambuco, 1999.

BASTOS FILHO, J. B.; SIQUEIRA, A. F. (Orgs.). Reflexões sobre os Fundamentos da Física Moderna. Maceió: Edufal, 1997.

CAPRIA, M. M. (Editor) La Costruzione dell'immagine scientifica del mondo. Napoli: La Città del Sole, 1999.

CAPRIA, M. M. (Editor) Scienze e Democrazia. Napoli: Liguori, 2003. 
CAPRIA, M. M. (Editor) Physics Before and After Einstein. Amsterdam: IOS, 2005.

CAPRIA, M. M. (Editor) Scienze, poteri e democrazia. Roma: Editori Riunit, 2006.

DIAMOND, J. M. Colapso: como as sociedades escolhem o fracasso ou o sucesso. São Paulo: Record, 2005.

MEYERS, R. Universe: the cosmology quest. Documentário lançado em 2004. Disponível em: <http://www.randallmeyers.com/films.php>.

NEVES, M. C. D. Santos-Dumont's invention of the first airplane propelled by own motor against the Wright brothers fallacy in the North American historiography of air technology. In: INTERNATIONAL CONFERENCE SCIENCE \& DEMOCRACY, 2003. Proceedings... Napoli: Istituto Italiano per gli Studi Filosofici.

NEVES, M. C. D. Do infinito, do mínimo e da inquisição em Giordano Bruno. Ilhéus: Editus, 2004

NEVES, M. C. D. Memórias do invisível: uma reflexão sobre a História no Ensino de Física e a Ética na Ciência. 2. ed. Maringá: EDUEM. 2008.

NEVES, M. C. D.; ARGÜEllo, C. A. Astronomia de régua e compasso: de Kepler a Ptolomeu. 2. ed. Campinas: Papirus, 2001.

André Koch Torres de Assis Instituto de Física

UNICAMP - SP 